\title{
Removal of methylene blue from aqueous solution using cocoa (Theobroma cacao) nib-based activated carbon treated with hydrochloric acid
}

\author{
Khairul Adli Nikman a, c , Fisal Ahmad b, Mohd Sukri Hassan a, ${ }^{*}$ \\ a Faculty of Science and Technology, Universiti Sains Islam Malaysia, 71800 Bandar Baru Nilai, Negeri Sembilan, Malaysia \\ b Cocoa Innovative and Technology Centre, Malaysian Cocoa Board, Lot 12621, 71800 Bandar Baru Nilai, Negeri Sembilan, Malaysia \\ c Department of Forensic Medicine, Hospital Kuala Lumpur, 50586 Kuala Lumpur, Malaysia \\ * Corresponding author: mohdsukri@usim.edu.my
}

Article history

Received 3 October 2018 Revised

18 January 2018

Accepted 10 April 2018

Published Online 4 June 2018

\begin{abstract}
Chemical activation process was applied to prepare a cocoa nib-based activated carbon using potassium carbonate $\left(\mathrm{K}_{2} \mathrm{CO}_{3}\right)$. The performance of the activated carbon in removing Methylene Blue from aqueous solution was investigated by batch adsorption studies. The adsorptive properties were studied in terms of initial concentration $\left(\mathrm{C}_{0}: 100-300 \mathrm{mg} / \mathrm{L}\right)$ and contact time effects. The experimental isotherm data fitted well the Langmuir and Temkin models. The adsorption kinetic followed the pseudosecond-order model and Boyd model explained the mechanism of adsorption. The results indicate that the chemically produced activated cocoa nib carbon has significant potential to be used as an adsorbent material for adsorption of Methylene Blue from aqueous solution.
\end{abstract}

Keywords: Cocoa nib-based activated carbon, Methylene Blue, Langmuir model, Temkin model, Boyd model

\section{INTRODUCTION}

The cellulosic originated precursors have been continually explored and tested as adsorbents. This is due to the fact that they possess significant values: abundant in nature, cheap, renewable and comparable with the conventional and commercial adsorbents (Lim and Aris, 2013). Agricultural wastes or by-products are an alternative source to be exploited in order to overcome issues on expensive precursor, regeneration and the effect of regeneration on adsorption capacity (Oladoja et al., 2008). Study on low cost and non-conventional adsorbent could offer significant opportunity for environmental sustainability and at the same time, recommend promising benefits to commercially transform the waste into promising prospects (Ahmad et al., 2012).

Some of the precursors used in the production of cellulosic-based or agricultural waste-based activated carbons in the recent past are cocoa shells (Ahmad et al., 2012; Mylsamy and Theivarasu, 2012), cocoa pod (Pua et al., 2013; Bello and Ahmad, 2011), peanut shells (Wu et al., 2013), rice straw (Ramangkoon et al., 2016), papaya seeds (Collin and Lee, 2008), olive stones (Larous and Meniai, 2016), coconut husk (Tan et al., 2008), coconut mesocarp (Ferreira et al., 2015), beet pulp (Dursun et al., 2005) and avocado kernel seed (Rodrigues et al., 2011). All of these carbons were successfully applied for the removal of contaminants from aqueous solution.

Contaminants such as dyes normally accumulate and remain in the environment for a substantial period due to their resistance to chemical and photo degradation. They have the potential to inhibit sunlight penetration and consequently jeopardise the living of aquatic organisms (Ahmad et al, 2012). Such dyes are Methylene Blue, Basic Red 29 and
Basic Yellow 28 which classify as cationic dyes. Therefore, physical and/or chemical management methods have to be used to remove the dyes from the water system. The use of activated carbon (AC) is one of the effective solutions (Lim and Aris, 2013).

Cocoa nibs $(\mathrm{CN})$ have not been received serious consideration as sorbent, as it is the main precursor in production of chocolate and other cocoa products. However, there are significantly high amounts of waste during the manufacturing processes. The valuable cocoa precursors are discarded after fermentation process due to some deformities and infections. The cocoa nibs are also discarded during winnowing process when the breaking process of the beans result in small fagmented cocoa nibs, which will be blown away during the process. The aim of this work is to convert cocoa nibs into activated carbon, in order to make better use of this agricultural waste. Therefore, the focus of this research was to evaluate the adsorption potential of the cocoa nib-based activated carbon (CNAC) in removing Methylene Blue (MB) from aqueous solutions.

\section{EXPERIMENTAL}

\section{Materials}

Potassium carbonate $\left(\mathrm{K}_{2} \mathrm{CO}_{3}\right.$, Systerm, $\left.99.5 \%\right)$ was used as the chemical activating agent, and hydrochloric acid ( $\mathrm{HCl}$, Merck, $30 \%)$ and sodium hydroxide $(\mathrm{NaOH}$, Essex, $99 \%)$ were used in $\mathrm{pH}$ balancing process. Commercial $\mathrm{MB}\left(\mathrm{C}_{16} \mathrm{H}_{18} \mathrm{C}_{1} \mathrm{~N}_{3} \mathrm{~S} \cdot 3 \mathrm{H}_{2} \mathrm{O}\right)$ textile dye was obtained from Sigma-Aldrich (M) Sdn Bhd, Malaysia. De-ionized water was used to prepare all reagents and solutions. 


\section{Preparation of deash activated carbon from cocoa nibs}

$\mathrm{CN}$ used for the preparation of activated carbon was obtained from Cocoa Innovative and Technology Centre, Cocoa Board Malaysia, Nilai, Negeri Sembilan, Malaysia. CN was washed with water to remove dirt and later dried at $105{ }^{\circ} \mathrm{C}$ for 24 hours to remove the moisture. $60 \mathrm{~g}$ of the dried $\mathrm{CN}$ was ground into small particles and sieved to the desired particle size of $0.5 \mathrm{~mm}$. The particles were then loaded into a stainless steel vertical tubular reactor $(\mathrm{l}: 130 \mathrm{~cm}, \mathrm{~d}: 38$ $\mathrm{mm}$ of 310 grade stainless steel) placed in a tubular furnace (Model Carbolite VST 12/110/900). Carbonization was carried out at $700{ }^{\circ} \mathrm{C}$ with heating rate of $10{ }^{\circ} \mathrm{C} / \mathrm{min}$ under purified nitrogen flow at a rate of $150 \mathrm{~cm}^{3} / \mathrm{min}$ for one hour.

In the second step, approximately 10.0 gram of char was impregnated with 10.0 gram of $\mathrm{K}_{2} \mathrm{CO}_{3}$ before activated under the same condition to a final temperature of $800{ }^{\circ} \mathrm{C}$ for one hour. The activated carbon produced, referred to as CNAC, was then cooled down under nitrogen flow until it reached a room temperature. The impregnation step was repeated with a combination of 10.0 gram char - 20.0 gram $\mathrm{K}_{2} \mathrm{CO}_{3}$ and 10.0 gram char -30.0 gram $\mathrm{K}_{2} \mathrm{CO}_{3}$ to achieve the desired ratios $(1: 1,1: 2$ and $1: 3)$.Then the CNAC was washed with hot deionized water for a few rounds and followed with $0.1 \mathrm{M}$ hydrochloric acid and $0.1 \mathrm{M} \mathrm{NaOH}$ until the $\mathrm{pH}$ of washing solution reached approximately $6.5-7.0$. The washing procedure was applied in order to remove the remaining $\mathrm{K}_{2} \mathrm{CO}_{3}$ (Adinata et al., 2007) and, $\mathrm{HCl}$ and $\mathrm{NaOH}$ were used to adjust the $\mathrm{pH}$.

Subsequently, the produced activated carbon was added into 250 $\mathrm{mL}$ beaker which contained $1 \mathrm{M}$ of $\mathrm{HCl}$, as a leach agent to remove minerals and ash from the carbon (Ahmad et al, 2013). A continuous controlled heat was supplied to the mixture by using a magnetic stirrer with heating ceramic plate (IKA ${ }^{\circledR}$ C-MAG HS7, Germany). The temperature controller was used to maintain a constant temperature (50 ${ }^{\circ} \mathrm{C}$ ) for one hour. A thermometer was placed in the beaker to monitor the temperature in real-time. After finished, the de-ash activated carbon was washed with hot deionized water and the $\mathrm{pH}$ was adjusted to $6.5-$ 7.0 with $\mathrm{HCl}(0.1 \mathrm{M})$ and $\mathrm{NaOH}(0.1 \mathrm{M})$. Fig. 1 summaries the process in a schemic diagram.

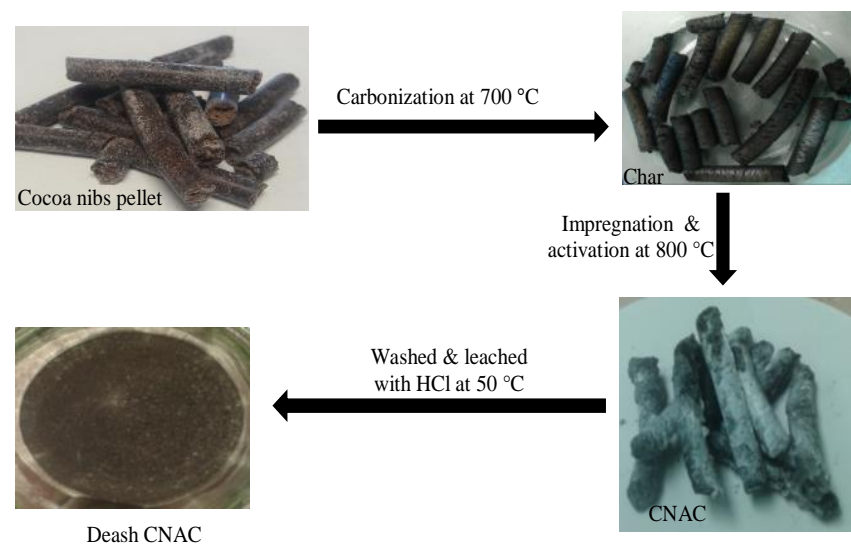

Fig. 1 Schematic diagram for preparation of deash cocoa nib-based activated carbon (de-ash CNAC).

\section{Surface area and porosity analysis of CNAC}

The prepared samples (activated carbon) were characterized by $\mathrm{N}_{2}$ gas adsorption using a Micromeritics ASAP 2010 surface area and porosity analyzer to measure its surface area and porosity. Prior analysis, the sample was degassed at $300{ }^{\circ} \mathrm{C}$ until evacuation was completed at $950 \mathrm{mmHg}$.

\section{Surface functional groups analysis}

Surface functional groups were determined using FTIR spectra which were recorded between 4000 and $400 \mathrm{~cm}^{-1}$ using an Agilent 630 FTIR spectrometer, US. Diamond ATR accessory was attached to the unit to perform a fast and simple collection of infra red (I R) spectrum. The analysis was performed automatically by MicroLab PC software attached to the system and data handling was assisted by ResPro.

\section{Morphological analysis}

Scanning electron microscope (SEM) was used to study the surface morphology of the precursors, chars and the activated carbon prepared including the pore structure, surface structure and pore arrangement. The analysis on surface morphology of the precursor, char and the produced activated carbon was performed using SEM (Model FEI Quanta 450, US).

\section{Batch equilibrium studies}

Batch equilibrium studies were carried out by adding a fixed amount of AC $(0.60 \mathrm{~g})$ each into each $250 \mathrm{~mL}$ Erlenmeyer flasks containing $100 \mathrm{~mL}$ of different concentrations $(50-400 \mathrm{mg} / \mathrm{L})$ of dye solution. The flasks were agitated in an isothermal water-bath shaker at $120 \mathrm{rpm}$ and $30^{\circ} \mathrm{C}$ until equilibrium was reached. Subsequently, the adsorbent was removed from the solution by filtration. The percentage removal of $\mathrm{MB}$ was calculated using (1) and the amount of adsorption at time (t), $q_{t}(\mathrm{mg} / \mathrm{g})$ was calculated using (2),

$$
\begin{aligned}
& \% \text { Removal of } M B=\frac{C_{i}-C_{e}}{C_{i}} \\
& q_{t}=\frac{C_{0}-C_{t}}{W} \times V
\end{aligned}
$$

where $C_{i}$ is the initial liquid-phase concentration of dye $(\mathrm{mg} / \mathrm{L}), C_{e}$ is the equilibrium liquid-phase concentration of dye $(\mathrm{mg} / \mathrm{L}), C_{0}$ is the initial liquid-phase concentration of dye $(\mathrm{mg} / \mathrm{L}), C_{t}$ is the liquid-phase concentration of dye at any time, $t(\mathrm{mg} / \mathrm{L}), V$ is the volume of the solution (L), and $W$ is the mass of dry adsorbent used (mg).

The final concentrations of the dye were measured using a double beam UV-Vis spectrophotometer (Model Cary 60 UV-Vis, Agilent, US) at the $\lambda_{\max }$ value $(668 \mathrm{~nm})$.

\section{Batch kinetics studies}

Similarly, the kinetics experimental procedures were identical to those of batch equilibrium studies. The aqueous samples with the adsorbent were agitated until equilibrium reached. The concentrations at different time intervals were taken and were measured similarly. MB removal at equilibrium, $q_{e}(\mathrm{mg} / \mathrm{g})$, was calculated using (2).

\section{RESULTS AND DISCUSSION}

\section{Characteristics of activated carbon}

Brunauer-Emmett-Teller (BET) surface area, mesopore surface area, total pore volume, mesopore volume and pore size of CNAC and de-ash CNAC are described in Table 1.

Table 1 shows the comparison between the CNAC and the acid (1 $\mathrm{M} \mathrm{HCl}$ ) treated CNAC. The ash content in CNAC was recorded at $14.77 \%$ of the whole weight, and the de-ash CNAC was left with 3.77 $\%$. The pore diameter was increased in de-ash CNAC compared with untreated CNAC which was from 4.93 to $5.52 \mathrm{~nm}$ (12\% increment). Other properties were also increased such as BET $(47 \%)$, mesopore surface area $(64 \%)$, total pore volume $(65 \%)$ and mesopore volume (40\%). Therefore, de-ash CNAC contained higher BET surface area and total pore volume compared with CNAC $\left(1,932 \mathrm{~m}^{2} / \mathrm{g}\right.$ and 2.67 , respectively) due to increasing of pore size.

The differences between both BET surface areas and total pore volumes were due to the acid leaching process. Similar observation was reported by Ahmad et al., (2013) where they suggested that acid treatment develops new structure that highly mesoporous. Acid treatment resulted in development of new structure that is highly mesoporous through elimination of carbonates and formation of amorphous silica (Ahmad et al., 2013).

The changes in porosity were due to the dissolution of cations from the $\mathrm{AC}$, which degraded the highly microporous structure to low microporous. The cation dissolution could lead to pore walls destruction which can create new pores and can reduce the density of the treated AC (Ahmad et al., 2013).

Fig. 2 (a) and (b) show the SEM micrographs of both the untreated CNAC and acid treated CNAC (de-ash) samples, respectively. In both 
(a) and (b), it can be observed that pores were developed on both surfaces. There were several pores formed on the CNAC surface but the surface of the de-ash CNAC contained more pores. This variation is believed due to that fact that the organic compounds were driven off after combustion however the silica remains were still available in the char structure. The treatment of hydrochloric acid ensures that silica was removed and more pores were obtained. The SEM results showed that the surface activated carbon which was treated with acid contains more well-developed pores where can provide a good surface for MB to be trapped and adsorbed (Hanum et al., 2017).

Table 1 Surface characteristics, proximate contents, and elemental analyses of char, CNAC and de-ash CNAC.

\begin{tabular}{lcc}
\hline \multicolumn{1}{c}{ Properties } & CNAC & De-ash CNAC \\
\hline BET surface area $\left(\mathrm{m}^{2} / \mathrm{g}\right)$ & $1,313.88$ & $1,932.36$ \\
Mesopore surface $\mathrm{area}\left(\mathrm{m}^{2} / \mathrm{g}\right)$ & 400.34 & 659.60 \\
Total pore volume $\left(\mathrm{cm}^{3} / \mathrm{g}\right)$ & 1.62 & 2.67 \\
Mesopore volume $(\%)$ & 30.47 & 42.68 \\
Pore diameter $(\mathrm{nm})$ & 4.93 & 5.52 \\
Ash content $(\%)$ & 14.77 & 3.77 \\
\hline
\end{tabular}
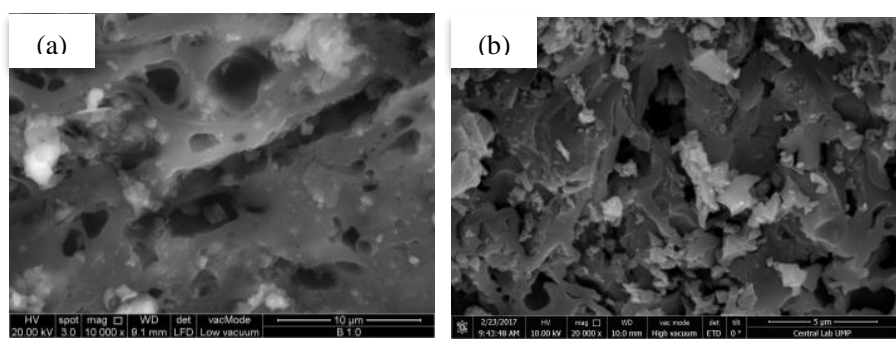

Fig. 2 (a) and (b) show the SEM micrographs of (a) untreated CNAC and (b) acid treated CNAC samples.

Fig. 3 shows the spectrum of the activated carbon samples (CNAC and de-ash CNAC). Both activated carbons developed a similar spectrum and exhibit similar peaks. There is no reduction in both spectrums between 3500 and $800 \mathrm{~cm}^{-1}$ except for a very weak band of $1570 \mathrm{~cm}^{-1}$ in (a), which was disappeared in (b). Result indicated that the acid treatment was not significant in altering the surface functional groups in the CNAC.

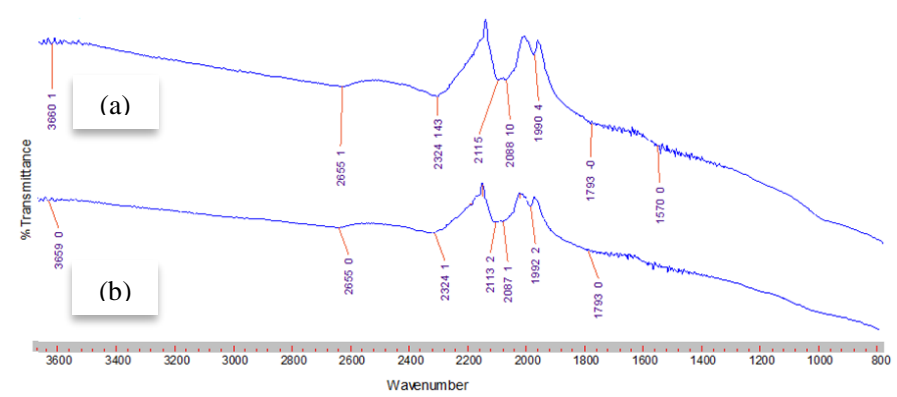

Fig. 3 (a) and (b) show the SEM micrographs of (a) untreated CNAC and (b) acid treated CNAC samples.

\section{Batch Adsorption Studies}

The adsorption isotherm shows the distribution of adsorption molecules between MB and the de-ash CNAC at an equilibrium state. The adsorption data was fitted to Langmuir, Freundlich and Temkin isotherm models to determine the suitable adsorption model (Rahimi and Vadi, 2014). The amount of MB adsorbed at the equilibrium time specifies the maximum adsorption uptake of the de-ash CNAC as shown in Fig. 4. This happened because of the abundant vacant sites on the adsorbent surface that were available for adsorption during the initial stage (Ahmad et al., 2012).

The adsorption data were investigated using Langmuir, Freundlich and Temkin isotherms. These isotherm models were explained by equation (3), (4) and (5), respectively (Abdel-Ghani et al., 2016):
$\frac{C_{e}}{q_{e}}=\frac{1}{Q_{o} K_{L}}+\frac{1}{Q_{o}}$

$\log \mathrm{q}_{\mathrm{e}}=\log \mathrm{K}_{\mathrm{f}}+\frac{1}{\mathrm{n}} \log \mathrm{C}_{\mathrm{e}}$

$\mathrm{q}_{\mathrm{e}}=\ln \mathrm{K}_{\mathrm{T}}+\mathrm{B} \ln \mathrm{C}_{\mathrm{e}}$

Using the linear form of the equations, the MB adsorption equilibrium of Langmuir, Freundlich and Temkin have been successfully plotted as shown in Fig. 5, 6 and 7, respectively. Table 2 summaries the values of MB isotherms constants calculated from the developed plots.

The essential characteristic of the Langmuir-type adsorption process can be signified with the dimensionless constant or separation factor, $R_{L}$ which has a value of $0<R_{L}<1$, where lower $R_{L}$ value indicates a favorable isotherm adsorbate/adsorbent (Ahmad et al., 2012). The $R_{L}$ is defined by equation (6) (Chowdury et al., 2011):

$$
R_{L}=\frac{1}{1+K_{L} C_{i}}
$$

where $K_{L}$ is the Langmuir constant $(\mathrm{L} / \mathrm{mg})$ and $C_{i}$ is the highest initial concentration $(\mathrm{mg} / \mathrm{L})$.

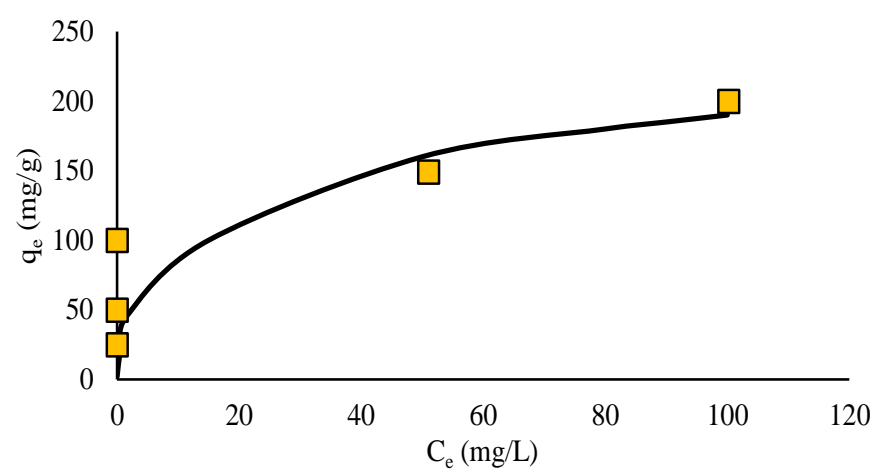

Fig. 4 Equilibrium adsorption of $\mathrm{MB}$ onto de-ash $\mathrm{CNAC}$ at $30^{\circ} \mathrm{C}$.

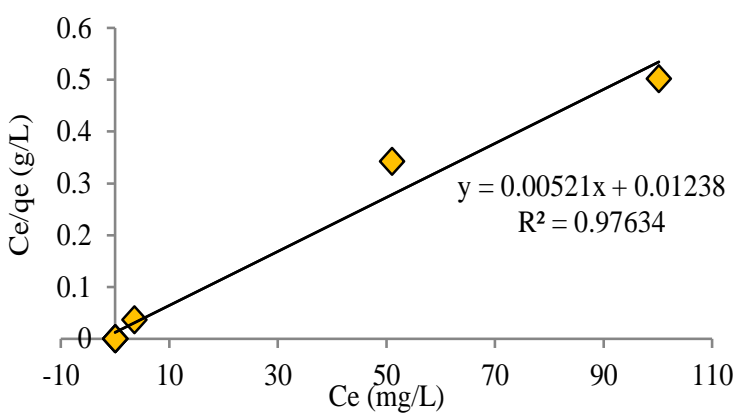

Fig. 5 Langmuir adsorption of MB onto de-ash CNAC.

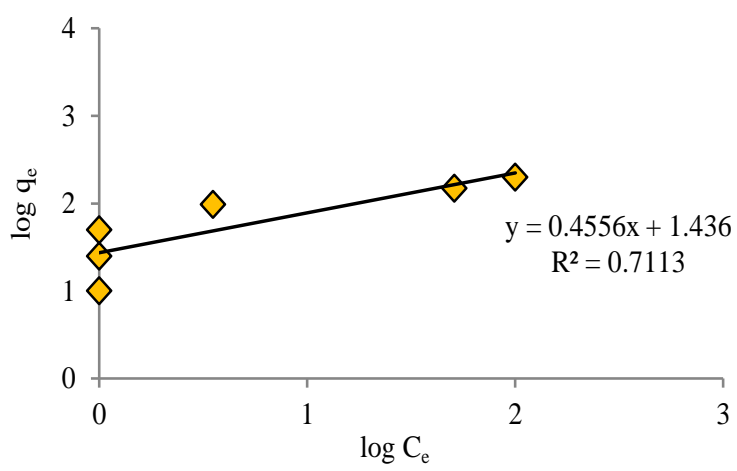

Fig. 6 Freundlich adsorption of MB onto de-ash CNAC. 


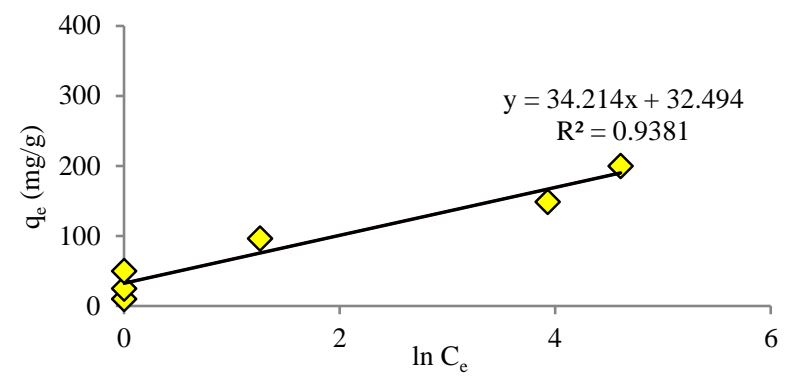

Fig. 7 Temkin adsorption of MB onto de-ash CNAC.

The adsorption data were well fitted with Langmuir isotherm model where the correlation coefficient, $R^{2}$ value is close to $1(0.9763)$. The higher correlation coefficient of 0.9763 for the Langmuir isotherm predicts the monolayer coverage of $\mathrm{MB}$ on the de-ash CNAC particles. A high value of $K_{L}(0.4208)$ and a low value of $R_{L}(0.0232)$ indicated a favorable solute/adsorbent adsorption process (Joseph and Xavier, 2013).

The Freundlich isotherm did not fit the data well, as the $R^{2}$ value is far from 1 . The $R^{2}$ value for Temkin isotherm is higher than Freundlich but lower than Langmuir, indicating agreement with the experimental data (Ahmad et al., 2012).

Table 2 Isotherm constants for adsorption of MB by CNAC.

\begin{tabular}{|c|c|c|c|c|}
\hline \multirow[t]{2}{*}{ Langmuir } & $R^{2}$ & $\begin{array}{c}q_{m} \\
(m g / g)\end{array}$ & $\begin{array}{c}K_{L} \\
(L / m g)\end{array}$ & $R_{L}$ \\
\hline & 0.97634 & 191.94 & 0.4208 & 0.0232 \\
\hline \multirow[t]{2}{*}{ Freundlich } & $R^{2}$ & $1 / n$ & $n$ & $\begin{array}{c}K_{f} \\
\left((m g / g)(m g / L)^{1 / n}\right)\end{array}$ \\
\hline & 0.7113 & 0.4556 & 2.1949 & 4.2038 \\
\hline \multirow[t]{2}{*}{ Temkin } & $R^{2}$ & $\begin{array}{c}A \\
(L / g) \\
\end{array}$ & $B$ & - \\
\hline & 0.9381 & 2.585 & 34.214 & - \\
\hline
\end{tabular}

The fact that the Freundlich isotherm did not fit the experimental data well may be due to a result of homogeneous distribution of active sites onto the cocoa nib-based activated carbon surface rather than heterogenous distribution. The Freundlich equation assumes multilayer adsorption on the surface as well as heterogeneous adsorption (Dogan et al., 2006). That is why the data were well fitted with Langmuir but not Freundlich isotherm model.

Table 3 lists other adsorbents with maximum monolayer adsorption capacity of MB. It can be observed that the de-ash CNAC had a relatively moderate adsorption capacity of $191.94 \mathrm{mg} / \mathrm{g}$ and nearly similar with cocoa shells $(212.77 \mathrm{mg} / \mathrm{g})$.

Table 3 Comparison of the maximum monolayer adsorption of Methylene Blue onto various adsorbents.

\begin{tabular}{|c|c|c|}
\hline Adsorbent & $\begin{array}{l}\text { Maximum } \\
\text { monolayer, } q_{\mathrm{e}} \\
(\mathrm{mg} / \mathrm{g})\end{array}$ & Reference \\
\hline Cocoa shell & 212.77 & Ahmad et al., 2012 \\
\hline Pecan nutshell & 400.00 & Bello-Huitle et al., 2010 \\
\hline $\begin{array}{l}\text { Crescentia } \\
\text { cujete fruit shell }\end{array}$ & 66.67 & Joseph and Xavier, 2013 \\
\hline $\begin{array}{l}\text { Jatropha curcas } \\
\text { fruit shell }\end{array}$ & 499.17 & Tongpoothorn et al., 2011 \\
\hline Pistachio hull & 389.00 & $\begin{array}{l}\text { Moussavi and Khosravi, } \\
2011\end{array}$ \\
\hline $\begin{array}{l}\text { Ricinus } \\
\text { communis } \\
\text { epicarp }\end{array}$ & 62.50 & $\begin{array}{l}\text { Santhi and Manonmani, } \\
2009\end{array}$ \\
\hline Cola nuts hell & 87.12 & $\begin{array}{l}\text { Nsami and Mbadcam, } \\
2013\end{array}$ \\
\hline Cocoa nibs & 191.94 & This work \\
\hline
\end{tabular}

\section{Adsorption Kinetic Studies}

The pseudo-first-order and pseudo-secondorder kinetic models were applied to evaluate the kinetic of adsorption of MB on de-ash CNAC. The pseudo-first-order and pseudo-second-order kinetic models were applied to evaluate the kinetic parameters of the adsorption process (Lagergren, 1998). The pseudo-first-order and the pseudo-second-order equations based on equilibrium adsorption are expressed as in equation 7 and 8, respectively (Ho and McKay, 2000):

$$
\begin{aligned}
& \ln \left(q_{e}-q_{t}\right)=\ln q_{e}-k_{1} t \\
& \frac{t}{q_{t}}=\frac{1}{k_{2} q_{e}^{2}}+\frac{1}{q_{e}} t
\end{aligned}
$$

Fig. 8 demonstrates the pseudo-first-order kinetic model to predict sorption kinetics. The values of $K_{1}$ and correlation coefficient, $R^{2}$ obtained from the plots for MB adsorption on the activated carbon are given in Table 4 . The experimental $q_{e}$ values were not in agreement with the calculated values obtained from the linear plots. In addition, lowest initial concentration ( $10 \mathrm{mg} / \mathrm{L})$ did not achieved high $R^{2}(0.812)$ values for MB adsorption.

Besides, it was observed that all initial dye concentrations, except for $10 \mathrm{mg} / \mathrm{L}$, the adsorption data were well represented by the pseudo first-order model only the first 30 to 40 minutes. This result suggests that the MB adsorption onto de-ash CNAC does not conform with the pseudo first-order adsorption model. The similar findings have also been observed in the adsorption of MB onto Crescentia cujete fruit shell (Joseph and Xavier, 2013), kenaf core fiber (Sajab et al, 2011) and palm kernel coat (Oladoja et al., 2009). The model is generally not applicable to be used for the whole range of contact time but only effective over the initial 30 minutes of the adsorption processes (Bulut et al. (2008). The result showed that the adsorption of MB on the cocoa nib-based activated carbon was not first-order.

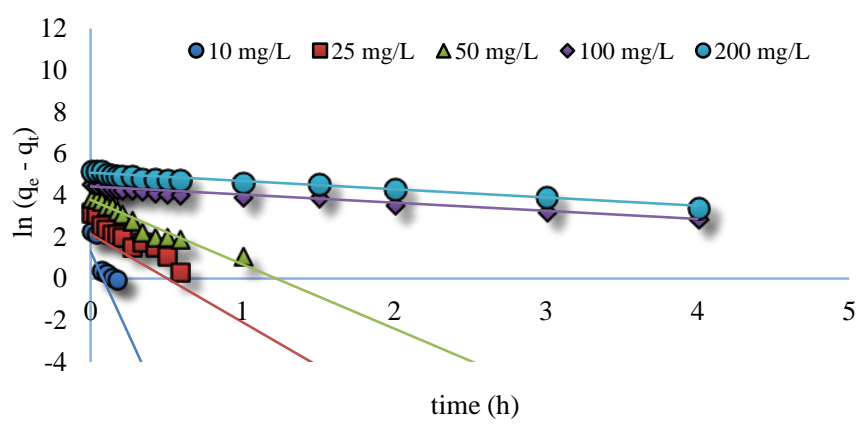

Fig. 8 Pseudo-first-order of MB kinetic adsorption.

Fig. 9 shows a linear plot of $t / q_{t}$ versus $t$ to represent the pseudosecond-order kinetic model. The graph showed good agreement between the experimental and the calculated $q_{e}$ values, as addressed in Table 4. The correlation coefficients $\left(R^{2}\right)$ for the linear plots of $t / q t$ against $t$ were observed to be close to 1 indicating the applicability of the second-order kinetic model to describe the MB adsorption process on the de-ash CNAC. It is clearly suggest that the adsorption kinetic of the $\mathrm{MB}$ was accurately described by the pseudo second-order adsorption model.

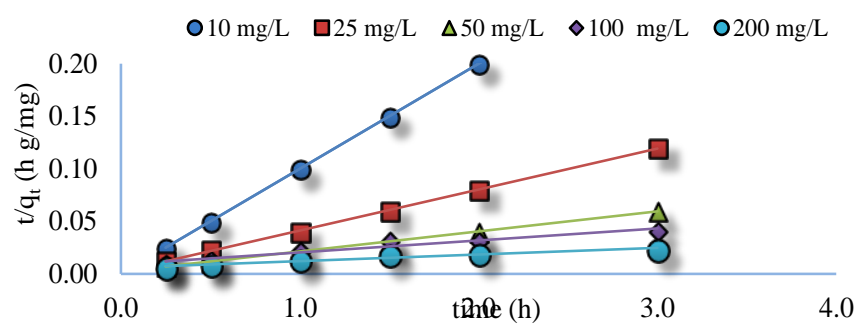

Fig. 9 Pseudo-second-order of MB kinetic adsorption. 
From Table 4, it was learn that the $R^{2}$ values for second-order model were higher than the first-order model. The higher $R^{2}$ value confirmed that the sorption data are well represented by pseudo-second-order kinetics model (Dogan et al., 2004).

Table 4 Kinetics model equation constants and correlation coefficients for MB adsorption.

\begin{tabular}{|c|c|c|c|c|c|c|}
\hline \multirow{3}{*}{ 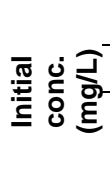 } & \multicolumn{6}{|c|}{ Kinetic models } \\
\hline & \multicolumn{3}{|c|}{ Pseudo-first-order } & \multicolumn{3}{|c|}{ Pseudo-second-order } \\
\hline & $\begin{array}{l}q_{e}, c a l \\
(\mathrm{mg} / \mathrm{g})\end{array}$ & $\begin{array}{c}K_{1} \\
(1 / \mathrm{h})\end{array}$ & $R^{2}$ & $\begin{array}{l}q_{e}, c a l \\
(\mathrm{mg} / \mathrm{g})\end{array}$ & $\begin{array}{c}K_{2} \\
(\mathrm{~g} / \mathrm{mg} \mathrm{h})\end{array}$ & $R^{2}$ \\
\hline 10 & 8.711 & 15.369 & 0.812 & 10.000 & 0.000 & 1.000 \\
\hline 25 & 19.508 & 4.081 & 0.916 & 25.641 & 0.691 & 0.995 \\
\hline 50 & 43.654 & 3.087 & 0.963 & 52.356 & 0.159 & 0.995 \\
\hline 100 & 83.188 & 0.390 & 0.963 & 87.719 & 0.014 & 0.942 \\
\hline 200 & 160.871 & 0.397 & 0.969 & 158.730 & 0.007 & 0.945 \\
\hline
\end{tabular}

*conc. - concentration

\section{CONCLUSION}

The CNAC was optimised using hydrochloric acid as leaching agent to remove remaining minerals that contribute to ash content. The de-ash CNAC was used to remove MB. The acid treatment was found to significantly increase the adsorption of MB. The treated carbon was characterized by nitrogen adsorption isotherm to determine its BET surface area, mesopore surface area, total pore volume, mesopore volume and average pore size and the values were $1,932.36 \mathrm{~m}^{2} / \mathrm{g}$, $659.60 \mathrm{~m}^{2} / \mathrm{g}, 290.03 \mathrm{~m} 2 / \mathrm{g}, 2.67 \mathrm{~cm}^{3} / \mathrm{g}, 42.68 \%$ and $5.52 \mathrm{~nm}$, respectively. The acid treatment process did not influence the composition of functional groups in the CNAC. The adsorption kinetics indicated that pseudo-second-order kinetic model fits the adsorption data, while the adsorption isotherm was well explained by Langmuir and Temkin isotherm models. The results of this study demonstrate that the adsorption capacity of CNAC can be optimized by hydrochloric acid treatment.

\section{ACKNOWLEDGEMENT}

This work was financially supported by the Malaysian Cocoa Board (MCB) under the Research Grant from Ministry of Science, Technology and Innovation (MOSTI), Malaysia.

\section{REFERENCES}

Adinata, D., Wan Daud, W. M. A., Aroua, M. K. 2007. Preparation and characterization of activated carbon from palm shell by chemical activation with $\mathrm{K}_{2} \mathrm{CO}_{3}$. Bioresource Technology, 98, 145-149.

Ahmad, F., Wan Daud, W. M. A., Ahmad, M., Radzi, R. 2013. The effects of acid leaching on porosity and surface functional groups of cocoa (Theobroma cacao)-shell based activated carbon. Chemical Engineering Research and Design, 1028-1038.

Ahmad, F., Wan Daud, W. M. A., Ahmad, M. A., Radzi, R. 2012. Cocoa (Theobroma cacao) shell-based activated carbon by $\mathrm{CO}_{2}$ activation in removing of Cationic dye from aqueous solution: Kinetics and equilibrium studies. Chemical Engineering Research and Design, 1480-1490.
Bello, O., Ahmad, M. A. 2011. Adsorptive removal of a synthetic textile dye using cocoa pod husks. Toxicological \& Environmental Chemistry, 93(7), 1298-1308.

Bulut, E., Ozacar, M., Sengil, I. A. 2008. Adsorption of malachite green onto bentonite: Equilibrium and kinetic studies and process design. Microporous and Mesoporous Materials, 234-246.

Chowdury, Z., Mohd. Zain, S., Atta Khan, R., Khalid, K. 2011. Linear regression analysis for kinetics and isotherm studies of sorption of manganese (II) ions onto activated palm ash from waste water. Oriental Journal of Chemistry, 27(2), 405-415.

Collin, J., Lee, M. 2008. Sorption kinetic studies of medical grade activated carbon prepared from papaya seeds. Modern Applied Science, 2(6), 115-123.

Dogan, M., Alkan, M., Türkyilmaz, A., Özdemir, Y. 2004. Kinetics and mechanism of removal of methylene blue by adsorption onto perlite. Journal of Hazardous Materials, B109, 141-148.

Dursun, G., Çiçek, H., Dursun, A. 2005. Adsorption of phenol from aqueous solution by using carbonised beet pulp. Journal of Hazardous Materials, 125(1), 175-182.

Ferreira, R., Couto Junior, O., Carvalho, K., Arroyo, P., Barros, M. 2015. Effect of solution $\mathrm{pH}$ on the Removal of paracetamol by activated carbon of dende coconut mesocarp. Chemical and Biochemical Engineering Quarterly, 47-53.

Hanum, F., Bani, O., Wirani, L. 2017. Characterization of activated carbon from rice husk by $\mathrm{HCl}$ activation and its application for lead $(\mathrm{Pb})$ removal in car battery wastewater. Materials Science and Engineering, 180.

Joseph, J. A., Xavier, N. 2013. Equilibrium and kinetic studies of Methylene blue onto activated carbon prepared form Crescentia cujete fruit shell. Nature and Science, 53-58.

Kumar, P., Kirthika, K. 2009. Equilibrium and kinetic study of adsorption of nickel from aqueous solution onto bael tree leaf powder. Journal of Engineering Science and Technology, 4(4), 351 - 363.

Larous, S., Meniai, A.-H. 2016. Adsorption of Diclofenac from aqueous solution using activated carbon prepared from olive stones. International Journal of Hidrogen Energy, 10380-10390.

Lim, A., Aris, A. 2013. A review on economically adsorbents on heavy metals removal in water and wastewater. Reviews in Environmental Science and Bio/Technology.

Mylsamy, S., Theivarasu, C. 2012. Adsorption of reactive dye using low cost adsorbent: Cocoa (Theobroma Cacao) Shell. World Journal of Applied Environmental Chemistry, 22-29.

Oladoja, N., Asia, I., Aboluwoye, C., Oladimeji, Y., Ashogbon, A. 2008. Studies on the sorption of basic dye by rubber (Hevea brasiliensis) Seed Shell. Turkish Journal of Engineering and Environmental Sciences, 32, 143-152.

Pua, F., Sajab, M., Chia, C., Zakaria, S., Abdul Rahman, I., Salit, M. 2013. Alkaline-treated cocoa pod husk as adsorbent for removing methylene blue from aqueous solutions. Journal of Environmental Chemical Engineering, 1, 460-465.

Rahimi, M., Vadi, M. 2014. Langmuir, Freundlich and Temkin adsorption isotherms of propranolol on multi-wall carbon nanotube. Journal of Modern Drug Discovery And Drug Delivery Research, 1-3.

Ramangkoon, S., Saenjum, C., Sirithunyalug, B. 2016. Preparation of rice straw activated charcoal by 2-step $\mathrm{H}_{3} \mathrm{PO}_{4}$ activation. International Journal of Pharmacy and Pharmaceutical Sciences, 8(4), 218-221.

Rodrigues, L., da Silva, M., Alvarez-Mendes, M., Coutinho, A., Thim, G. 2011. Phenol removal from aqueous solution by activated carbon produced from avocado kernel seeds. Chemical Engineering Journal, 174(1), 49-57.

Sajab, M., Chia, C., Zakaria, S., Jani, S., Ayob, M., Chee, K., . . Chiu, W. 2011. Citric acid modified kenaf core fibres for removal of methylene blue from aqueous solution. Bioresource Technology, 102, 7237-7243.

Tan, I., Ahmad , A., Hameed, B. 2008. Adsorption of basic dye on high-surfacearea activated carbon prepared from coconut husk: Equilibrium, kinetic and thermodynamic studies. Journal of Hazardous Materials, 154(1), 337-346.

Wu, M., Guo, Q., Fu, G. 2013. Preparation and characteristics of medicinal activated carbon powders by $\mathrm{CO}_{2}$ activation of peanut shells. Powder Technology, 188-196. 